\title{
Theoretical potential of agrovoltaic systems in Europe: a preliminary study with winter wheat
}

\author{
Brecht Willockx \\ Departement Elektrotechniek (ESAT) \\ KU Leuven \\ Ghent, Belgium \\ brecht.willockx@kuleuven.be
}

\author{
Bert Herteleer \\ Departement Elektrotechniek (ESAT) \\ KU Leuven \\ Ghent, Belgium \\ bert.herteleer@kuleuven.be
}

\author{
Jan Cappelle \\ Departement Elektrotechniek (ESAT) \\ KU Leuven \\ Ghent, Belgium \\ jan.cappelle@kuleuven.be
}

\begin{abstract}
This study presents an evaluation of the potential of agrovoltaic (combined use of photovoltaic systems and crop production) systems in Europe, using a python-based agrovoltaic simulation tool. The evaluation is based on three criteria: the PV energy yield, potential crop yield, and the agronomic impact of the agrovoltaic system on the biomass yield. Results confirm that the potential of PV energy increases with decreasing latitude, i.e. higher solar insolation levels. In contrast, the potential agricultural yield of winter wheat mainly depends on the variety of the crop and its ability to absorb light in shaded conditions. The leaf area index will be a crucial parameter in order to evaluate the performance in agrovoltaic conditions. It is concluded that the biggest potential in Europe for agrovoltaic systems with winter wheat is situated around the Mediterranean region, with a high PV performance, limited grain yield losses and a high potential of additional protection against heat stress and drought by agrovoltaic structures.
\end{abstract}

Index Terms-Agrivoltaic, Agrovoltaic, Simulation tool, European potential, Photovoltaic application, WOFOST

\section{INTRODUCTION}

The European Commission aims to make Europe the first carbon-neutral continent by 2050 [1]. One of the objectives of the green deal is to develop a power sector based on renewable sources, complemented by the rapid phasing out of coal and decarbonising gas. A way to accomplish this goal is to increase the share of solar energy production (the share of PV in the total electrical energy generation in 2017 was only $3.8 \%$ [2]). A recent study [3] investigated different land cover types, where the biggest solar potential of approximately $28 \mathrm{~W} / \mathrm{m}^{2}$ for future solar modules is considered on croplands. However, one of the concerns by large solar energy expansion is the increased land competition, with reduced area of crop land as consequence; the area of arable land per person is already decreasing with $1.5 \%$ per year while future food demand is increasing [4].

A possible solution for these concerns are agrovoltaic systems. These dual land use systems combine crop and energy production. Several installations have been built all over Europe, but what is currently missing to date is a preliminary study showing the theoretical agrovoltaic potential across all the member states of the European Union.

The theoretical agrovoltaic potential depends on two factors:
- Photovoltaics (PV) [Wh $/ \mathrm{m}^{2}$ for PV]: the incident solar radiation and other relevant climatic parameters such as ambient temperature and wind speed;

- Agronomy [\% biomass loss]: the impact of the agrovoltaic structure on crop, soil and biodiversity level.

A suitable crop to explore this theoretical potential in Europe is winter wheat (T. aestivum L.). It is widespread across the member states, often used as cover crop and considered as the most important staple crop in Europe with a cultivated area of almost $24 \mathrm{Mha}$ [5] and a production of $152 \mathrm{Mt}$ [4].

This study aims to shows the potential of agrovoltaic installations by estimating the solar potential $\left[\mathrm{Wh} / \mathrm{m}^{2} \mathrm{PV}\right]$, potential winter wheat grain yields $[\mathrm{kg} / \mathrm{ha}]$ and agronomic impact [\% biomass remaining] for the EU27 member states. These early yield forecasts will be crucial for policy making within renewable energy support schemes and the Common Agricultural Policy (CAP).

\section{MATERiALS AND METHODS}

\section{A. Simulation model}

The MARS Crop Yield Forecasting Systems (MCYFS) [6] of the Joint Research Centre (JRC) is used to monitor crop growth and yield forecasting over all countries of the European Union (EU28). One of the components of MCYFS is CGMS (Crop Growth Monitoring System) [7].

This study uses the python version of the CGMS (Crop Growth Monitoring System), pyCGMS [8], to estimate the influence of the agrovoltaic system on the winter wheat production. The crop simulator, integrated in pyCGMS, is based on WorldFoodStudies (WOFOST) [9], a mechanistic and dynamic crop model which uses a daily time step as its time resolution. WOFOST is capable of calculating the potential and water-limited biomass yield. This study will focus on the potential production which is mainly defined by the temperature, solar radiation and crop parameters (phenology, $\mathrm{CO}_{2}$ assimilation, respiration, dry matter partitioning, ...). The soil moisture for this situation is assumed to be constant at field capacity (i.e. perfect water balance: this is only valid when there is enough rainfall or irrigation to prevent drought stress).

Winter wheat has periods of establishment and first growth, a period of vegetative growth (tillering and head development), 
a period of flowering (anthesis) and a period of grain filling and ripening. The lengths of these periods can be calculated on the basis of temperature sums, and in this way, different winter varieties are described in the WOFOST simulations: $T_{\text {SUM1 }}\left[{ }^{\circ} \mathrm{C} \cdot\right.$ day $]$ describes the thermal requirement to reach anthesis (flowering) and $T_{\mathrm{SUM} 2}\left[{ }^{\circ} \mathrm{C} \cdot\right.$ day $]$ represents the thermal requirement during the reproductive period till maturity date.

WOFOST offers the advantage of an integrated distinction between sunlit and sun shaded leaves during assimilation and the calculation of winter wheat vernalisation requirements. Pests, diseases, weed and/or extreme weather events (like high temperatures and hail) are at this stage not yet integrated.

\section{B. Database description}

The CGMS database covers 1) weather data, 2) crop parameters and 3) agromanagement information on a spatial resolution of $25 \mathrm{~km}$ matching the Lambert Azimuthal Equal Area projection. The European area is divided in small grid cells as shown in Fig. 1.

1) The weather database includes: the daily minimum $T_{\min }$ $\left[{ }^{\circ} \mathrm{C}\right]$ and maximum temperature $T_{\max }\left[{ }^{\circ} \mathrm{C}\right]$, daily average wind speed $V_{\text {data }}[\mathrm{m} / \mathrm{s}]$, daily vapour pressure $p_{\text {data }}$ [hPa], daily incoming solar irradiance $G_{\text {data }}\left[\mathrm{W} / \mathrm{m}^{2}\right]$, snowfall and precipitation $I_{\text {data }}[\mathrm{mm}]$. This dataset is publicly available [10] and based on a daily collection of data coming from 4200 weather states in Europe, interpolated for all grid cells.

2) Gridded crop parameters, which represent the different winter wheat varieties across Europe, are initially based on work from the 1990s [11], and are later refined with grid specific calibrated phenological parameters $\left(T_{\mathrm{SUM} 1}\right.$ and $T_{\mathrm{SUM} 2}$ ) and vernalisation parameters (saturated vernalisation requirement VERNSAT) [12].

3) Agromanagement information such as sowing dates, are also grid specific and calibrated in previous work, based on the optimal temperature for vernalisation [12].

\section{Model set-up}

The presence of an agrovoltaic systems has two major consequences regarding the solar insolation at crop level:

- Solar radiation distribution: the homogeneity of incoming solar insolation is affected, this leads to practical issues, especially for field crops (e.g. to harvest the field in one go);

- Solar radiation reduction: too high solar insolation reductions will lead to unacceptable crop yield losses [13]. Note that this is standard practice for the "normal" ground mounted PV plants.

One option found in literature to tackle these consequences is increasing the elevation of solar modules, with a tilt of 15 degrees, placed in a South West orientation [14]. Fig. 2 shows the schematic representation of the considered agrovoltaic system. This fictitious structure, based on the Fraunhofer ISE test-setup [15], is placed with a height taken at $5 \mathrm{~m}$ to ensure

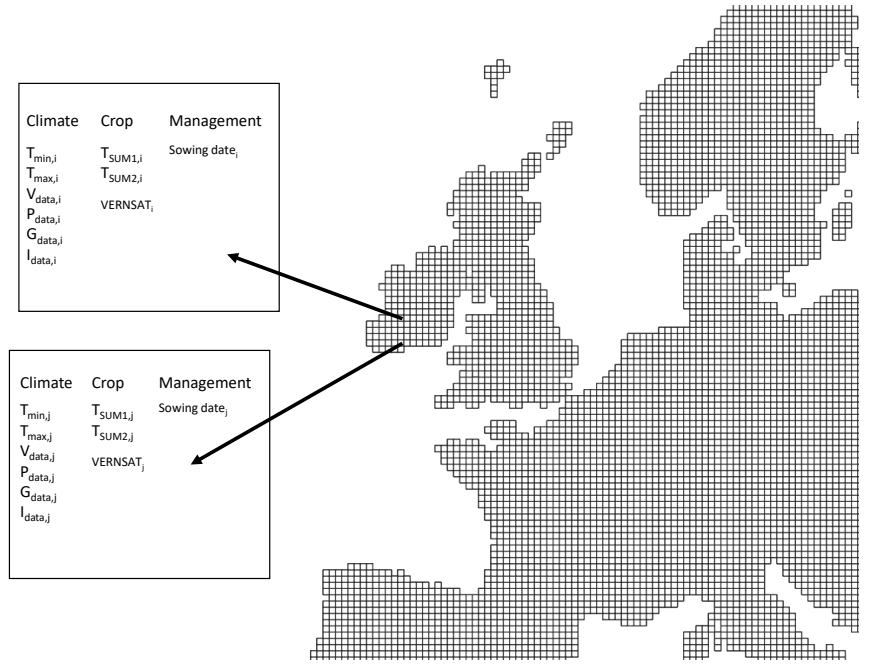

Fig. 1. European area divided in $25 \mathrm{~km} \mathrm{x} 25 \mathrm{~km}$ grid cells, each cell has specific climatic, crop and agromanagement data, as illustrated for the $i^{\text {th }}$ and $j^{\text {th }}$ cell

that most common grain harvesters can drive underneath the PV structure.

It is assumed in this preliminary study that the agrovoltaic structure influences all grid cells in the same way: there is a sustained amount of diffuse sunlight of $95 \%$ assumed and the direct sun light is blocked during approximately one third of the day, both resulting in a daily reduction of $20 \%$ photosynthetically active radiation (solar light in the $400 \mathrm{~nm}$ to $700 \mathrm{~nm}$ wavelength range used for photosynthesis).

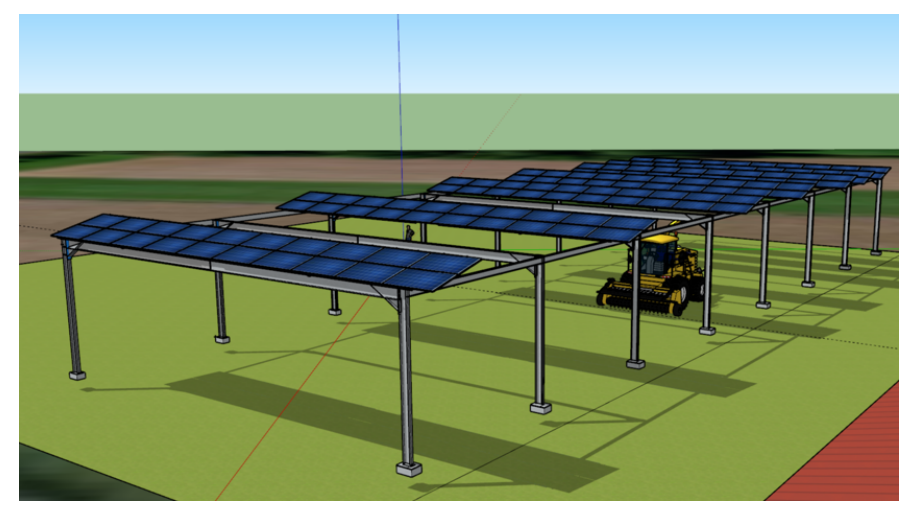

Fig. 2. Schematic representation of an agrivoltaic system.

The following paragraphs discuss the integration of this agrovoltaic system in the pyCGMS simulation environment.

1) Energy component: This study introduces an extra component to the pyCGMS tool in order to have a prediction of the potential PV energy yield. The energy component starts with estimating the average daily PV cell efficiency $\eta_{\text {cell }}$, in function of the daily average air temperature and wind speed. The chosen PV modules have an STC efficiency of $20.5 \%$ and a power temperature coefficient of $-0.39 \% /{ }^{\circ} \mathrm{C}$. The daily average wind speed data in the CGMS database is given at 
a height of $10 \mathrm{~m}$ and adjusted to the wind speed at the PV module's height $(5 \mathrm{~m})$. This wind speed is used to estimate the module's temperature, according to the model of Faiman [16]. Constants in this model $U_{0}$ and $U_{1}$ are taken at respectively 26.9 and 6.2 (c-Si).

The average solar radiation (in $\mathrm{W} / \mathrm{m}^{2}$ ) during the day is calculated by dividing the daily horizontal irradiance by the day length, without consideration of soiling, angle of incidence losses and spectral mismatches. The cell temperature is calculated with the Sandia's Cell Temperature Model [17], where the temperature difference between the backsheet and cell is taken at $3{ }^{\circ} \mathrm{C}$. The estimation of the daily average PV cell efficiency is multiplied with daily horizontal irradiance in order to show the potential solar energy production during simulation. This is an acceptable simplification, considering the temporal resolution of the crop component.

2) Crop component: WOFOST assumes a sinusoidal course of incoming radiation over the day. Normally, a three-point Gaussian integration method is applied to calculate the daily $\mathrm{CO}_{2}$ assimilation. The agrovoltaic structure affects the sinusoidal course; the reduced diffuse sunlight and blocked direct component lead to a specific dynamic radiation pattern. An example is given in Fig. 3; the considered SouthWest orientation will split the blocked direct component in two periods. The position of the blocked direct component is daily adapted and shifted, to address the change in declination of the sun path. When the direct light is blocked, the whole canopy is considered shaded and the $\mathrm{CO}_{2}$ assimilation rate of sun shaded leaves is applied. This in contrast with the $\mathrm{CO}_{2}$ assimilation rate of sunlit leaves, which is used when the direct light reaches the crops. The instantaneous assimilation rates are integrated by an Euler integration scheme to calculate the daily $\mathrm{CO}_{2}$ assimilation.

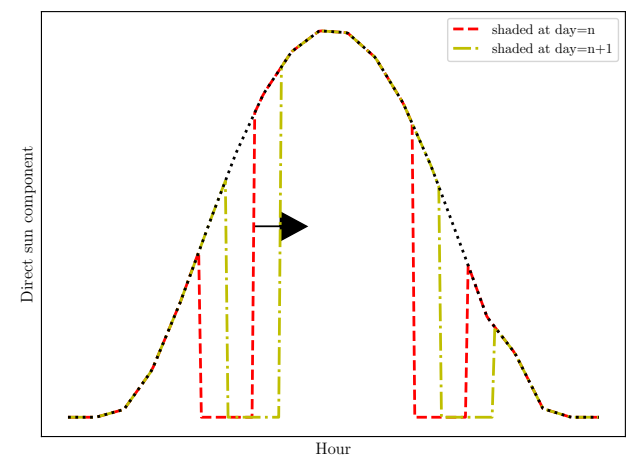

Fig. 3. Illustration of the daily direct sun component in agrovoltaic conditions. The direct component is blocked one third of the day and is shifted daily.

Changes in air temperature and humidity in this study are assumed to change slowly, due to the high elevation of the agrovoltaic structure. Besides that, studies of Marrou [13] show that the influence of marginally changes in air conditions on winter wheat yield would be rather small, explained by the long crop cycle.

\section{RESULTS AND DISCUSSION}

The simulations were run over the gridded European CGMS data for the year 2016-2017 (considered a representative year without extreme weather events like drought) and are plotted with QGIS [18].

\section{A. Potential of solar energy}

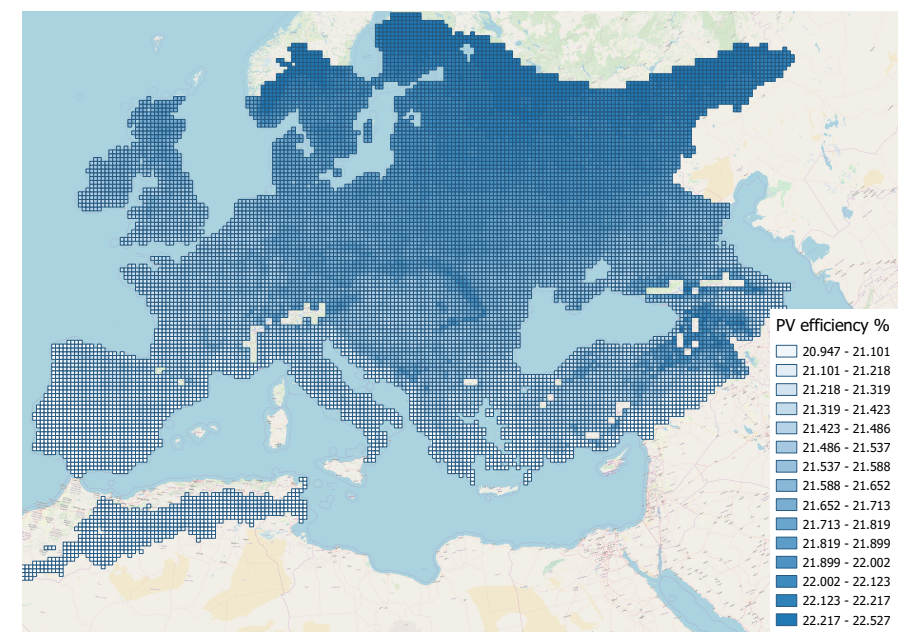

Fig. 4. Average daily PV efficiency simulated.

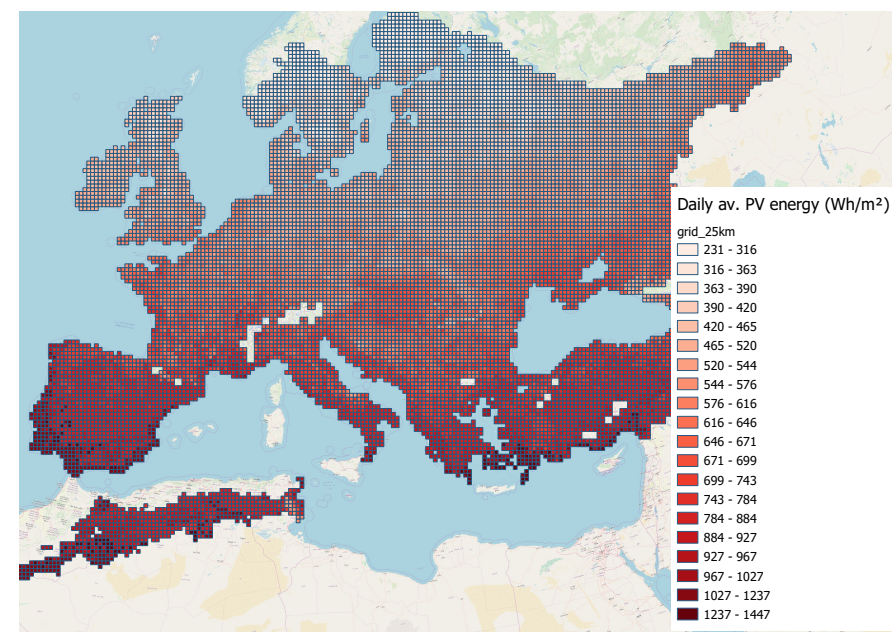

Fig. 5. Average daily PV energy production simulated.

Fig. 4 shows the temperature influence on the PV cell efficiency. The module temperature is estimated with the average daily solar irradiance, based on the daily insolation and day length. This means that the module temperature is underestimated; no account was taken of the high peak radiation levels during the day. Consequently, the PV cell efficiencies will be overestimated. However, these assumptions are considered acceptable, where the intention of this study is to show the reader or future policy maker the energy potential across Europe and the methodology is applied for all grid cells.

Despite the higher PV efficiencies in the colder Northern and Central Europe, the major effect on the potential solar 
energy is the incident solar insolation, as shown in Fig. 5. The PV energy yield increases with decreasing latitude (and higher solar insolation levels).

\section{B. Potential of biomass yield}

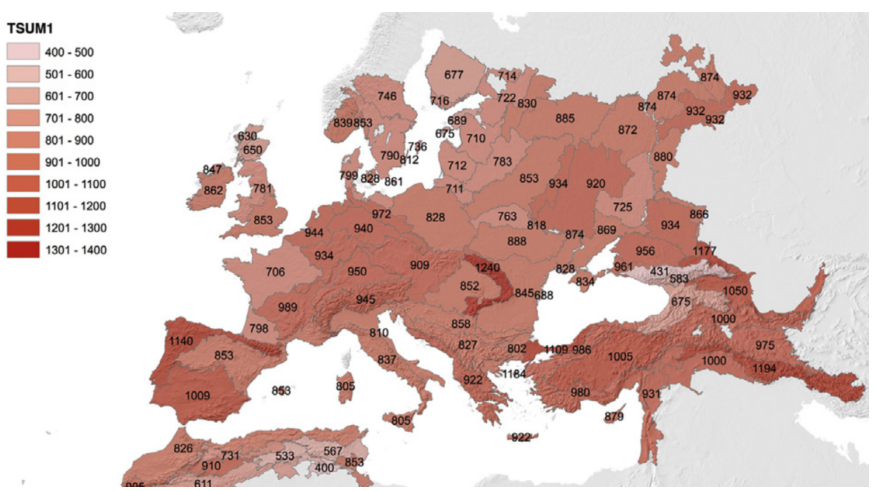

Fig. 6. Calibrated $T_{\text {SUM1 }}$ for winter wheat in different agro-environmental zones in Europe, reflecting the thermal time between sowing and flowering (anthesis), from [12], Fig 5a.

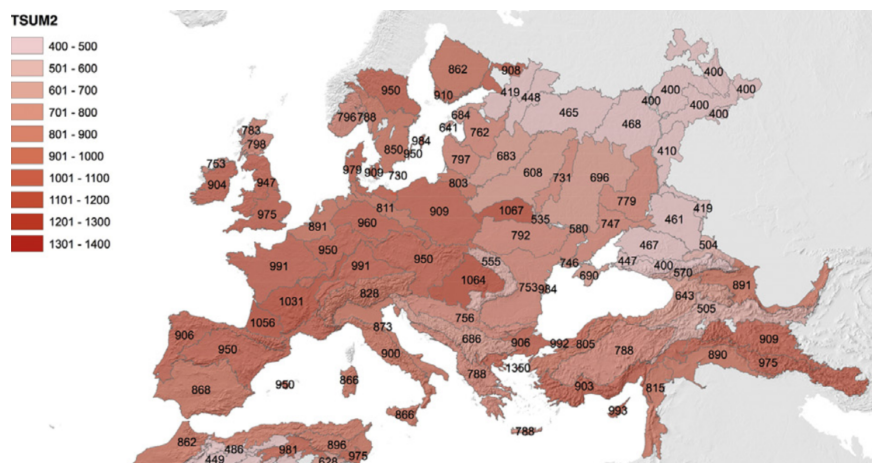

Fig. 7. Calibrated $T_{\text {SUM2 }}$ for winter wheat in different agro-environmental zones in Europe, reflecting the thermal time between flowering and maturity, from [12], Fig 5b.

The different winter wheat varieties were calibrated in previous work [12] and shown in Fig. 6 and Fig. 7. As explained earlier, $T_{\mathrm{SUM} 1}$ describes the period from emergence to flowering, where the main part of the assimilates are allocated to the roots and leaves. $T_{\mathrm{SUM} 2}$ is the period from flowering until maturity date, where all assimilates are allocated to the grains. Consequently, the highest grain yields $[\mathrm{kg} / \mathrm{ha}]$ are located in coastal areas with long grain filling periods and mild weather conditions as shown in Fig. 8. These places have a high Harvest Index (HI, i.e. the ratio of grain yield to the total above-ground biomass). In contrast, other wheat varieties with a shorter cycle chosen in the Eastern European member states (to prevent drought and heat stress during the grain filling period) result in lower grain yields.

The impact of the agrovoltaic structure on the grain yield is shown with relative numbers ( $1=$ unaffected yield $)$ in Fig. 9. Although the shade pattern and daily reduction of $20 \%$ insolation apply equally to all grid cells, a varying

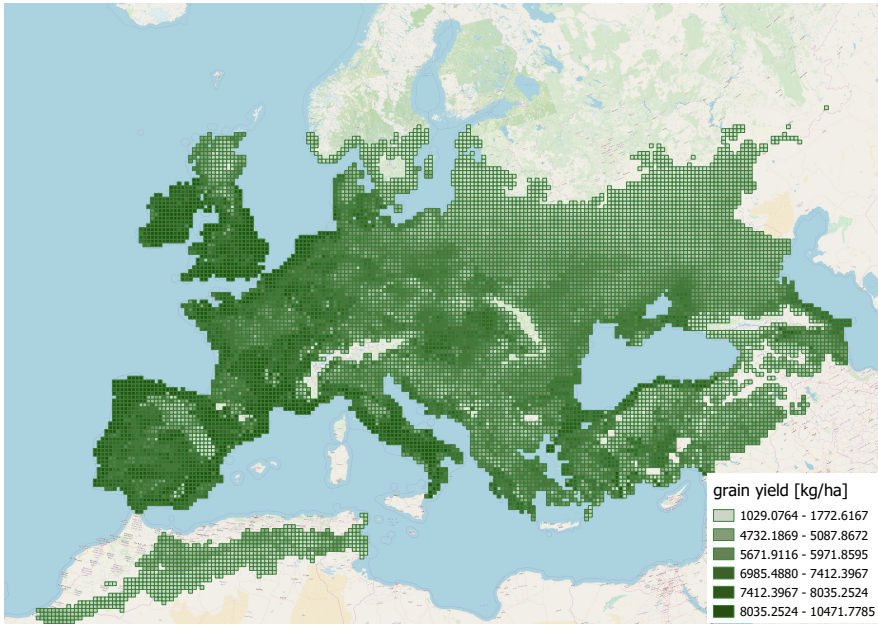

Fig. 8. Baseline potential grain yield simulated without agrovoltaic influence.

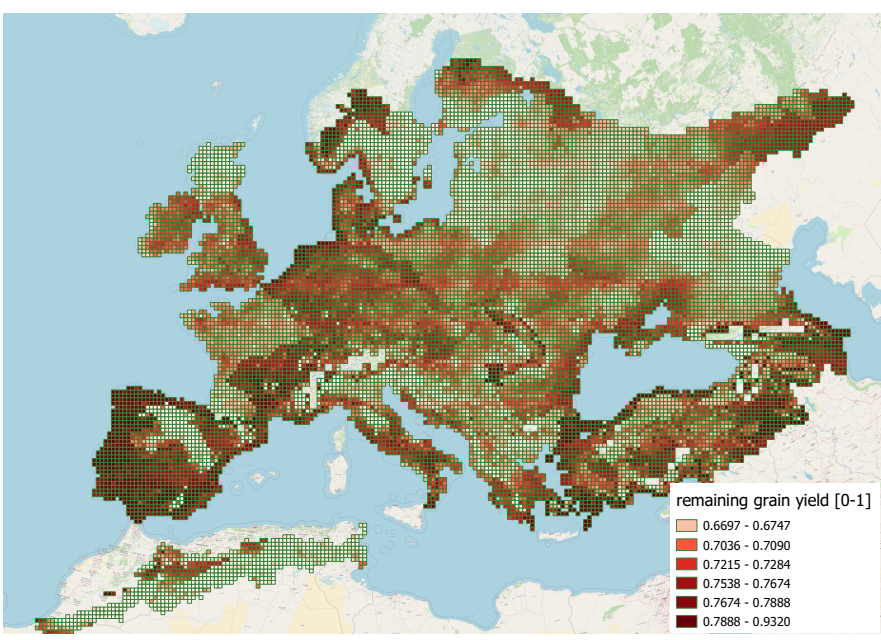

Fig. 9. Relative remaining grain yield (0-1) in agrovoltaic conditions compared to the baseline, lower values indicate largest crop losses. The applied shade pattern is equal for all grid cells.

reduction between $7 \%$ and $35 \%$ in biomass yield is estimated, with no clear correlation with solar insolation levels. A first explanation can be found by the PAR light saturation point: the assimilation rates per unit leaf area are not linear with the absorbed PAR radiation, there is a PAR light saturation point around $320 \mathrm{~W} / \mathrm{m}^{2}$, which means that higher PAR levels do not further increase the assimilation rates. A second explanation can be found by looking at the characteristics of the different varieties of winter wheat cultivated across Europe. This therefore suggest that there is a strong correlation between the period's length from emergence to flowering $\left(T_{\mathrm{SUM} 1}\right)$ and the grain yield loss (as can be noticed for Benelux countries and South Spain). Indeed, a longer period until flowering means that more assimilates are located to the leaves, resulting in larger leaf areas. These larger leaf areas are not economically beneficial on their own, but they improve the canopy light interception during the critical period of grain filling in shaded conditions. The crop is now able to absorb more direct light 
during the sunlit periods and more scattered diffuse light during the shaded periods. This finally results in higher canopy assimilation rates and subsequently reduced grain yield loss.

An example to illustrate this effect is given by an comparison between Belgium $\left(52.72^{\circ} \mathrm{N} ; 4.76^{\circ} \mathrm{E}\right)$ and South France $\left(43.58^{\circ} \mathrm{N} ; 0.01^{\circ} \mathrm{E}\right)$ at flowering in Fig. 10 . This figure clearly shows the discrete PAR pattern below the PV array with higher levels in South France. As a consequence, the integrated assimilation rates (i.e. vertical integration over canopy depths, which takes into account the self-shading of the lower leaves) per unit leaf area are also higher, with a notable saturation at $25 \mathrm{~kg} / \mathrm{ha} / \mathrm{h}$.

Due to the longer cycle from emergence to flowering in calendar days (which is the effect of a milder climate in Belgium and higher $\left.T_{\mathrm{SUM} 1}\right)$, the leaf area index is almost 2 times higher than in South France. The whole canopy is now able to absorb more PAR light, resulting in higher integrated canopy assimilation rates and reduced grain yield losses.
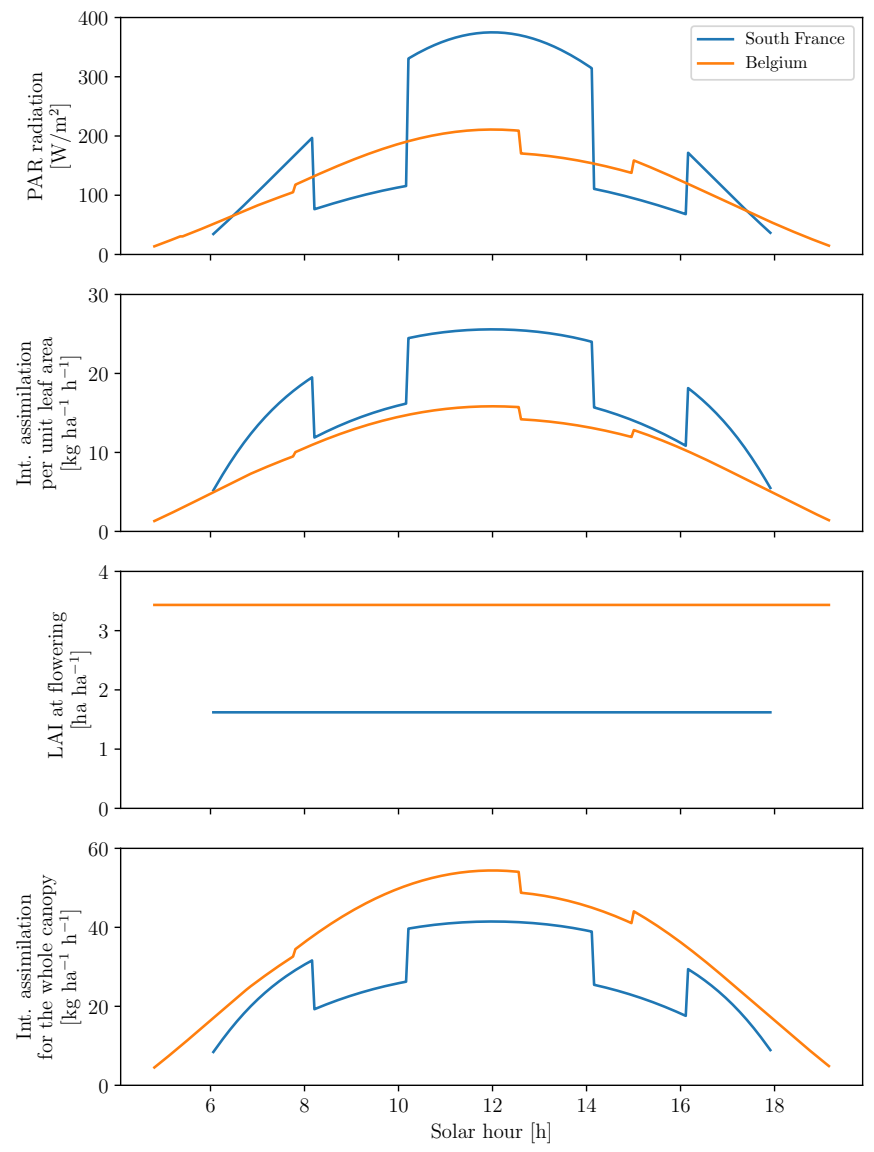

Fig. 10. Comparison of canopy assimilation rates between Belgium and South France at flowering. Although South France sees higher PAR levels, the canopy assimilation rate in Belgium is higher, explained by its larger leaf area as result of a longer crop cycle in calendar days.

It can be concluded that there is no clear correlation between solar insolation level and grain yield losses. This can be explained by two facts: 1) the assimilation rates per unit leaf area are limited by the light saturation point: this limits assimilation during sunlit periods 2) the high influence of light interception ability at flowering (given by the Leaf Area Index, which can be used as performance indicator as shown in Fig. 11): varieties with a better light canopy interception ability are capable to better perform during the critical reproductive (grain filling) stage in shaded conditions. In this preliminary study, where no morphologic and phenological traits are considered [19], the improved light interception is mainly the result of a longer period between emergence to flowering.

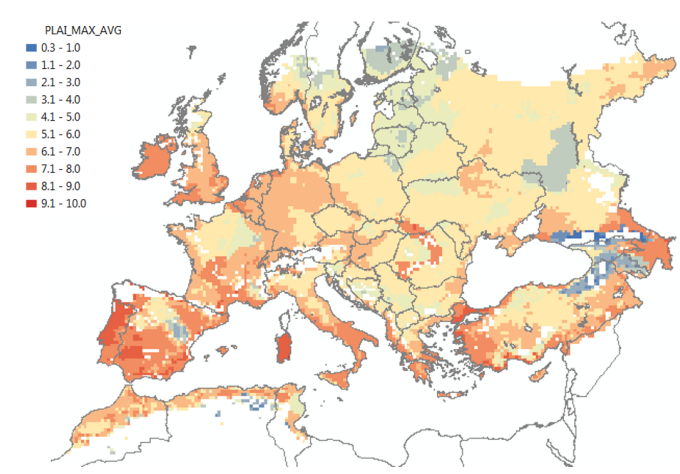

Fig. 11. The average maximum potential leaf area index for the different winter wheat varieties across Europe, from [12], S4b

\section{DiscuSSION AND FUTURE WORK}

This study presents a theoretical potential of agrovoltaic systems with winter wheat in Europe by an python based simulation tool. A fictitious agrovoltaic structure is assumed, which reduces the available insolation by $20 \%$ for all locations by a specific dynamic (discrete) shade pattern. Our preliminary results show the well-known effect that the PV yield $\left[\mathrm{Wh} / \mathrm{m}^{2}\right.$ of PV] increases with decreasing latitude; i.e. with higher solar insolation levels.

More complex is the grain yield performance which is not directly driven by the location specific solar insolation. This can initially explained by the light compensation point, which limits the leaf assimilation rate [20] during sunlit periods. However, we believe that the major effect results from the winter wheat variety and more specific, its light harvesting ability (leaf area) at flowering. It is shown that varieties with a longer cycle until flowering (and lower Harvest Index HI) are less sensitive to shade in the grain filling period than varieties with smaller cycles. This means that the performance of an agrovoltaic system (for the same crop type) can be influenced by the choice of an adequate variety. However, it must be stated that current varieties are already used according to other environmental impact factors. For example, the variety chosen in the Eastern countries, has generally a smaller cycle $\left(T_{\mathrm{SUM} 1}+T_{\mathrm{SUM} 2}\right)$, with lower leaf areas and a lower agrovoltaic performance as consequence. However, these smaller cycles are beneficial to the absolute yield because they prevent heat and drought stress occurring at later dates.

Considering the PV performance, absolute grain yields and agronomic impact of the agrovoltaic systems with current 
winter wheat varieties, these early results show that the highest agrovoltaic potential with winter wheat is situated around the South Mediterranean Region (e.g. Spain, South-East France, Italy,... ).

Nevertheless, it should be mentioned that the crop simulator used for this study, WOFOST, has at this stage still some limitations: it cannot simulate cold and heat stresses, excess water, damage by hail and strong winds and other extreme weather events. Additionally, physiological and morphological traits [21] are not yet integrated. Knowing that for example in the Mediterranean area, very high (leaf) temperatures kill flowers or seeds and increased leaf areas in shaded conditions are observed [19], the impact of agrovoltaic systems for these region is much more positive than currently predicted, which further highlight its high potential.

This study simulates only the theoretical agrovoltaic potential. These results (e.g. potential grain yield and potential PV performance) are only valid in ideal circumstances. It will be useful in future work to also estimate the technical potential:

- PV: generated energy per unit land area. The technical PV yield depends on the ground coverage ratio (\%), which is location dependent to address a reduction of $20 \%$ in solar insolation.

- Agronomy: water-limited yield. This is more realistic and also dependent on the water availability, where there is an impact of agrovoltaic systems on evapotranspiration and drought [22], [23].

\section{SUMMARY OF THE WORK}

Agrovoltaic systems can be a solution for the increasing land competition between food and energy production. This work estimated the theoretical agrovoltaic potential in Europe for different winter wheat varieties in a python-based simulation tool. Grid specific climate data and crop parameters were applied to calculate 1) the PV energy yield, 2) the potential biomass yield and 3) the agronomic impact on a specific dynamic shade pattern. In line with previous work, the PV yield increases with increasing insolation level (decreasing latitude). In contrast, the change in grain yield is less sensitive to the insolation level due its assimilation light saturation point. This suggests that the performance of an agrovoltaic system mainly depends on the crop variety and its ability to absorb as much as possible light in a shaded environment, where the leaf area index can act as an indicator.

The potential for agrovoltaic systems is especially high for the South Mediterranean region: the PV performance is high due the high insolation, the grain yield losses are limited by the shade pattern due possible morphological traits, and there is a high probability of additional protection against heat stress and drought, and shade fractions are limited, which is positive for the technical potential and PV array density.

\section{REFERENCES}

[1] E. Commission, "Communication from the commission: the european green deal," December 2019. Online; accessed 21-January-2020.

[2] Eurostat, "Electricity production, consumption and market overview," June 2019. Online; accessed 05-June-2020.
[3] E. Hassanpour, S. Good, M. Calaf, and C. Higgins, "Solar pv power potential is greatest over croplands," Scientific Reports, vol. 9, 122019.

[4] E. Agriculture and R. Development, "Eu agricultural outlook: Arable land area to continue its decline," November 2019. Online; accessed 17-January-2020.

[5] Eurostat, "Crop production in eu standard humidity," January 2020. Online; accessed 21-January-2020.

[6] C. LAZAR and G. Genovese, "Methodology of the mars crop yield forecasting system, agrometeorological modelling," Processing and Analysis, vol. 2, pp. 10-31, 012004.

[7] B. Bouman, C. Diepen, P. Vossen, and T. van der Wal, "Simulation and systems analysis tools for crop yield forecasting," Applications of systems approaches at the farm and regional levels. Volume 1. Proceedings of the second international symposium on Systems Approaches for Agricultural Development, held at IRRI, Los BaAos, Philippined, 6-8 December 1995. Kluwer Academic Publishers, Dordrecht, pp. 325-340, 011997.

[8] d. W. Allard, "pycgms," 2019.

[9] I. Supit, A. Hoojer, and C. Van Diepen, System description of the Wofost 6.0 crop simulation model implemented in CGMS. Volume 1: Theory and Algorithms. 011994.

[10] I. Biavetti, S. Karetsos, A. Ceglar, A. Toreti, and P. Panagos, "European meteorological data: contribution to research, development, and policy support," vol. 9229 , pp. $31-39,2014$

[11] P. Boons, G. Koning, and C. Van Diepen, "Crop-specific simulation parameters for yield forecasting across the european community," Simulation Reports CABO-TT, No.32, CABO-DLO, 011993.

[12] A. Ceglar, R. Wijngaart, and A. Wit, "Improving wofost model to simulate winter wheat phenology in europe: Evaluation and effects on yield," Agricultural Systems, 052018.

[13] H. Marrou, L. Guilioni, L. Dufour, C. Dupraz, and J. Wery, "Microclimate under agrivoltaic systems: Is crop growth rate affected in the partial shade of solar panels?," Agricultural and Forest Meteorology, vol. 177, no. August, pp. 117-132, 2013.

[14] M. Beck, G. Bopp, A. Goetzberger, T. Obergfell, C. Reise, and S. Schindele, "Combining pv and food crops to agrophotovoltaic: Optimization of orientation and harvest," EUPVSEC proceedings, 012012.

[15] S. Schindele, M. Trommsdorff, A. Schlaak, T. Obergfell, G. Bopp, C. Reise, C. Braun, A. Weselek, A. Bauerle, P. Högy, A. Goetzberger, and E. Weber, "Implementation of agrophotovoltaics: Techno-economic analysis of the price-performance ratio and its policy implications," Applied Energy, vol. 265, p. 114737, 2020.

[16] D. Faiman, "Assessing the outdoor operating temperature of photovoltaic modules," Progress in Photovoltaics: Research and Applications, vol. 16, pp. $307-315,062008$.

[17] D. King, J. Kratochvil, and W. Boyson, Photovoltaic Array Performance Model. PhD thesis, 012004.

[18] QGIS Development Team, QGIS Geographic Information System. Open Source Geospatial Foundation, 2009.

[19] M. G. Arenas Corraliza, V. Rolo, M. L. López-Díaz, and G. Moreno, "Wheat and barley can increase grain yield in shade through acclimation of physiological and morphological traits in mediterranean conditions," Scientific Reports, vol. 9, 072019.

[20] D. Wang, Y. Sun, Y. Lin, and Y. Gao, "Analysis of light environment under solar panels and crop layout," 062017.

[21] H. Marrou, J. Wéry, L. Dufour, C. Dupraz, H. Marrou, J. Wéry, L. Dufour, C. D. Productivity, H. Marrou, J. Wery, L. Dufour, and C. Dupraz, "Productivity and radiation use efficiency of lettuces grown in the partial shade of photovoltaic panels To cite this version : HAL Id : hal-01137075 Productivity and radiation use efficiency of lettuces grown in the partial shade of," European Journal of Agronomy, Elsevier, vol. 44, pp. 54-66, 2013.

[22] G. Barron-Gafford, M. Pavao-Zuckerman, R. Minor, L. Sutter, I. BarnettMoreno, D. Blackett, M. Thompson, K. Dimond, A. Gerlak, G. Nabhan, and J. Macknick, "Agrivoltaics provide mutual benefits across the food-energy-water nexus in drylands," Nature Sustainability, 092019.

[23] Y. Elamri, B. Cheviron, J. M. Lopez, C. Dejean, and G. Belaud, "Water budget and crop modelling for agrivoltaic systems: Application to irrigated lettuces," Agricultural Water Management, vol. 208, no. April, pp. $440-453,2018$. 